\title{
Experimental and Theoretical Investigation and NBO Analysis on the Structure of Pregabalin
}

\author{
S. HARIKRISHNAN ${ }^{*}$ and T.J.BHOOPATHY \\ PG and Research Department of Physics, Pachaiyappa's College, \\ Chennai- 600030, Tamilnadu, India \\ subramaniharikrishnan@gmail.com
}

Received 30 October 2013, Accepted 22 November 2013

\begin{abstract}
A systematic vibrational spectroscopic assignment and analysis of pregabalin has been carried out by using FTIR, FT-Raman spectral data. The vibrational analysis were aided by electronic structure calculations-hybrid density functional methods (B3LYP) performed with 6$31 \mathrm{G}(\mathrm{d}, \mathrm{p})$ basis set. Molecular equilibrium geometries, electronic energies, natural bond order analysis, IR intensities, and harmonic vibrational frequencies have been computed. The assignments proposed based on the experimental IR and Raman spectra have been reviewed and selected assignment of the observed spectra have been proposed. The electronic properties, such as HOMO and LUMO energies and $\lambda_{\max }$ were determined by time-dependent DFT (TD-DFT) method. The thermodynamic functions of the title molecule were also performed using DFT method.
\end{abstract}

Keywords: Pregabalin, Vibrational spectra, DFT

\section{Introduction}

Pregabalin is an anticonvulsant drug used for neuropathic pain and as an adjunct therapy for partial seizures with or without secondary generalization in adults ${ }^{1}$. It has also been found effective for generalized anxiety disorder and is (as of 2007) approved for this use in the European Union and Russia ${ }^{1}$. It was designed as a more potent successor to gabapentin. Pregabalin is marketed by Pfizer under the trade name Lyrica. Pfizer described in an SEC filing that the drug could be used to treat epilepsy, post-herpetic neuralgia, diabetic peripheral neuropathy and fibromyalgia. Sales reached a record $\$ 3.063$ billion in $2010^{2}$. It is effective at treating some causes of chronic pain such as fibromyalgia but not others. It is considered to have a low potential for abuse, and a limited dependence liability if misused, but is classified as a Schedule V drug in the U.S $\mathrm{S}^{3}$.

In our present work, an attempt has been made to interpret the vibrational spectra of pregabalin by applying density functional theory calculations based on Becke3- Lee-Yang-Parr (B3LYP) level using 6-31G(d,p) basis set. Further, the calculation of electronic excitations, particularly for valence-like transitions and oscillator strength of pregabalin, were calculated employing the all valence electron TD-DFT methods. In addition to these atomic charges calculated at the B3LYP/6-31G(d,p) level. Experimentally observed spectral data of the title compound is found to be well comparable with the data obtained by quantum mechanical methods. 


\section{Experimental}

The solid phase FTIR spectrum was recorded in the region $4000-400 \mathrm{~cm}^{-1}$ in evacuation mode on Nexus 670 DTGS using KBr pellet technique with $4.0 \mathrm{~cm}^{-1}$ resolution. The FTRaman spectrum was recorded using $1064 \mathrm{~nm}$ line of Nd:YAG laser as excitation wavelength in the region $5000-100 \mathrm{~cm}^{-1}$ on Bruker IFS $66 \mathrm{~V}$ spectrometer equipped with FRA 106 Raman module was used as an accessory.

\section{Computational details}

To provide complete information regarding the structural characteristics and the fundamental vibrational modes of pregabalin the DFT-B3LYP correlation functional calculations have been carried out. The calculations of geometrical parameters in the ground state were performed using the Gaussian $03^{4}$ programs, invoking gradient geometry optimization ${ }^{5}$ on Intel core i3/2.93 GHZ processor. The geometry optimization was carried out using the initial geometry generated from standard geometrical parameters at DFT-B3LYP methods adopting 6-31G(d,p) basis set to characterize all stationary points as minima. The optimized structural parameters of the compound pregabalin were used for harmonic vibrational frequency calculations resulting in IR and Raman frequencies together with intensities. In DFT methods, Becke's three parameter exchange-functional (B3) ${ }^{6,7}$ combined with gradient-corrected correlation functional of Lee, Yang and Parr (LYP) ${ }^{8}$ by implementing the split-valence polarized $6-31 \mathrm{G}(\mathrm{d}, \mathrm{p})$ basis set ${ }^{9,10}$ have been utilized for the computation of molecular structure optimization, vibrational frequencies, thermodynamic properties and energies of the optimized structures.

\section{Results and Discussion}

\section{Molecular geometry}

The molecular structure of pregabalin belongs to $C_{1}$ point group symmetry. All vibrations are active in both IR and Raman. The optimized structure parameters of pregabalin calculated by DFT-B3LYP levels are listed in the Table 1 in accordance with the given Figure 1 atom numbering scheme of pregabalin. Table 1 compares the calculated bond lengths and angles for pregabalin with those experimentally available data ${ }^{11}$. From the theoretical values, we can find that most of the optimized bond angles are slightly larger than the experimental values due to the theoretical calculations belonging to isolated molecules in gaseous phase and the experimental results belonging to the molecule in the solid state. In spite of the differences, calculated geometric parameters represent a good approximation and they are the basis for calculating other parameters, such as vibrational frequencies and thermodynamic properties.

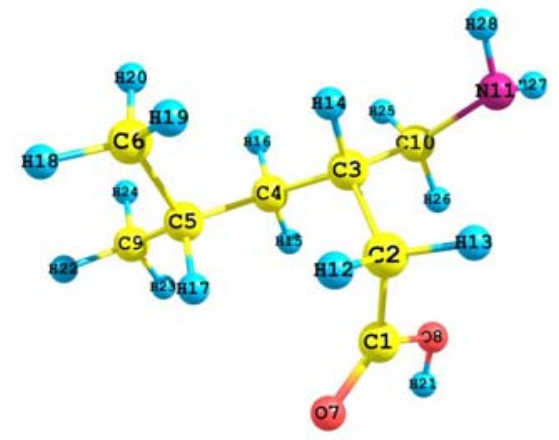

Figure 1. Atom numbering scheme of pregabalin 
Table 1. Structural parameters of pregabalin

\begin{tabular}{|c|c|c|}
\hline \multirow{2}{*}{ Structural parameters } & \multicolumn{2}{|l|}{ Pregabalin } \\
\hline & B3LYP/6-31G(d,p) & Experimental $^{11}$ \\
\hline \multicolumn{3}{|l|}{ Internuclear distance $\left(\mathrm{A}^{\circ}\right)$} \\
\hline $\mathrm{R}(1-2)$ & 1.46 & 1.51 \\
\hline $\mathrm{R}(1-7)$ & 1.21 & 1.21 \\
\hline $\mathrm{R}(1-8)$ & 1.34 & 1.34 \\
\hline $\mathrm{R}(2-3)$ & 1.46 & 1.52 \\
\hline $\mathrm{R}(2-12)$ & 1.10 & 1.11 \\
\hline $\mathrm{R}(2-13)$ & 1.09 & 1.11 \\
\hline $\mathrm{R}(3-4)$ & 1.52 & 1.52 \\
\hline $\mathrm{R}(3-10)$ & 1.52 & 1.52 \\
\hline $\mathrm{R}(3-14)$ & 1.10 & 1.11 \\
\hline $\mathrm{R}(4-5)$ & 1.55 & 1.52 \\
\hline $\mathrm{R}(4-15)$ & 1.10 & 1.11 \\
\hline$R(4-16)$ & 1.11 & 1.11 \\
\hline $\mathrm{R}(5-6)$ & 1.54 & 1.52 \\
\hline $\mathrm{R}(5-9)$ & 1.55 & 1.52 \\
\hline $\mathrm{R}(5-17)$ & 1.10 & 1.11 \\
\hline$R(6-18)$ & 1.09 & 1.11 \\
\hline $\mathrm{R}(6-19)$ & 1.10 & 1.11 \\
\hline$R(6-20)$ & 1.10 & 1.11 \\
\hline $\mathrm{R}(8-21)$ & 1.02 & 1.00 \\
\hline $\mathrm{R}(9-22)$ & 1.09 & 1.11 \\
\hline $\mathrm{R}(9-23)$ & 1.09 & 1.11 \\
\hline $\mathrm{R}(9-24)$ & 1.10 & 1.11 \\
\hline $\mathrm{R}(10-11)$ & 1.46 & 1.44 \\
\hline $\mathrm{R}(10-25)$ & 1.10 & 1.11 \\
\hline $\mathrm{R}(10-26)$ & 1.11 & 1.11 \\
\hline $\mathrm{R}(11-27)$ & 1.02 & 1.02 \\
\hline $\mathrm{R}(11-28)$ & 1.02 & 1.02 \\
\hline \multicolumn{3}{|l|}{ BOND ANGLE $(\AA)$} \\
\hline $\mathrm{A}(2-1-7)$ & 128.2 & 120.00 \\
\hline $\mathrm{A}(2-1-8)$ & 114.3 & 120.00 \\
\hline$A(1-2-3)$ & 111.2 & 109.50 \\
\hline$A(1-2-12)$ & 107.1 & 109.40 \\
\hline $\mathrm{A}(1-2-13)$ & 109.0 & 109.4 \\
\hline $\mathrm{A}(7-1-8)$ & 116.3 & 119.9 \\
\hline $\mathrm{A}(1-8-21)$ & 99.7 & 120.0 \\
\hline $\mathrm{A}(3-2-12)$ & 110.9 & 109.4 \\
\hline $\mathrm{A}(3-2-13)$ & 109.6 & 109.4 \\
\hline $\mathrm{A}(2-3-4)$ & 114.8 & 109.5 \\
\hline $\mathrm{A}(2-3-10)$ & 113.5 & 109.4 \\
\hline $\mathrm{A}(2-3-14)$ & 105.6 & 109.4 \\
\hline $\mathrm{A}(12-2-13)$ & 108.9 & 109.5 \\
\hline $\mathrm{A}(4-3-10)$ & 110.1 & 109.4 \\
\hline
\end{tabular}

Contd... 


\begin{tabular}{|c|c|c|}
\hline $\mathrm{A}(4-3-14)$ & 107.5 & 109.4 \\
\hline $\mathrm{A}(3-4-5)$ & 118.8 & 109.4 \\
\hline $\mathrm{A}(3-4-15)$ & 111.0 & 109.4 \\
\hline $\mathrm{A}(3-4-16)$ & 104.6 & 109.4 \\
\hline $\mathrm{A}(10-3-14)$ & 104.5 & 109.5 \\
\hline $\mathrm{A}(3-10-11)$ & 113.0 & 109.4 \\
\hline$A(3-10-25)$ & 104.4 & 109.4 \\
\hline $\mathrm{A}(3-10-26)$ & 111.3 & 109.4 \\
\hline $\mathrm{A}(5-4-15)$ & 109.1 & 109.4 \\
\hline $\mathrm{A}(5-4-16)$ & 106.7 & 109.4 \\
\hline$A(4-5-6)$ & 113.2 & 109.4 \\
\hline$A(4-5-9)$ & 111.1 & 109.4 \\
\hline $\mathrm{A}(4-5-17)$ & 108.3 & 109.4 \\
\hline$A(15-4-16)$ & 105.9 & 109.5 \\
\hline$A(6-5-9)$ & 110.4 & 109.4 \\
\hline $\mathrm{A}(6-5-17)$ & 107.7 & 109.4 \\
\hline $\mathrm{A}(5-6-18)$ & 110.3 & 109.4 \\
\hline $\mathrm{A}(5-6-19)$ & 112.4 & 109.4 \\
\hline$A(5-6-20)$ & 111.7 & 109.4 \\
\hline$A(9-5-17)$ & 105.7 & 109.4 \\
\hline$A(5-9-22)$ & 109.9 & 109.4 \\
\hline $\mathrm{A}(5-9-23)$ & 111.2 & 109.4 \\
\hline $\mathrm{A}(5-9-24)$ & 112.1 & 109.4 \\
\hline $\mathrm{A}(18-6-19)$ & 107.0 & 109.4 \\
\hline $\mathrm{A}(18-6-20)$ & 107.7 & 109.4 \\
\hline$A(19-6-20)$ & 107.4 & 109.4 \\
\hline $\mathrm{A}(22-9-23)$ & 107.7 & 109.4 \\
\hline $\mathrm{A}(22-9-24)$ & 107.6 & 109.4 \\
\hline $\mathrm{A}(23-9-24)$ & 108.1 & 109.4 \\
\hline $\mathrm{A}(11-10-25)$ & 106.6 & 109.4 \\
\hline$A(11-10-26)$ & 114.6 & 109.4 \\
\hline$A(10-11-27)$ & 108.1 & 120.0 \\
\hline $\mathrm{A}(10-11-28)$ & 110.2 & 119.9 \\
\hline$A(25-10-26)$ & 106.1 & 109.4 \\
\hline $\mathrm{A}(27-11-28)$ & 106.2 & 119.9 \\
\hline
\end{tabular}

\section{Electronic properties}

The energies of four important molecular orbitals of pregabalin: the highest and second highest occupied MO's (HOMO and HOMO-1), the lowest and the second lowest unoccupied MO's (LUMO and LUMO+1) were calculated and are presented in Table 2. The lowest singlet $\rightarrow$ singlet spin-allowed excited states of pregabalin were taken into account for the TD-DFT calculation in order to investigate the properties of electronic absorption. The calculations were also performed with methanol solvent effect. The calculated absorption wavelengths $\lambda_{\max }$, oscillator strength, excitation energies and the experimental wavelengths are also given in Table 2. The energy gap between HOMO and LUMO is a critical parameter in determining molecular electrical transport properties ${ }^{12}$. TD-DFT calculations using B3LYP/6$31 \mathrm{G}(\mathrm{d}, \mathrm{p})$, predict three intense electronic transitions at $\lambda_{\max }=247.56 \mathrm{~nm}, \mathrm{f}=0.0120$; $\lambda_{\max }=226.81 \mathrm{~nm}, \mathrm{f}=0.0002$ and $\lambda_{\max }=198.79 \mathrm{~nm}, \mathrm{f}=0.0100$ are in agreement with the 
experimental electronic transitions at $\lambda_{\max } 198.79 \mathrm{~nm}$. The experimental $\lambda_{\max }$ values are obtained from the UV/Visible spectra recorded as reported earlier ${ }^{13}$. In the electronic absorption spectrum of pregabalin, there are three absorption bands with a maximum 247.56 $\mathrm{nm}$. The strong absorption band $247.56 \mathrm{~nm}$ is caused by the $n \rightarrow \pi^{*}$ and the other two calculated value moderately intense bands are due to $\pi \rightarrow \pi^{*}$ transitions. The $\pi \rightarrow \pi^{*}$ transitions are expected to occur relatively at lower wavelength, due to the consequence of the extended aromaticity of the structure. The HOMO and LUMO diagram as shown in Figure 2.

Table 2. Experimental and calculated absorption wavelenght $(\lambda)$, excitation energies(E), oscillator strength(f) and frontier orbital energies of Pregabalin by TD-DFT method

\begin{tabular}{|c|c|c|c|c|c|c|c|c|}
\hline$\lambda$ Expt.;nm & $\lambda$ Cal.;nm & $\mathrm{E}, \mathrm{eV}$ & f & Assignment & $\begin{array}{c}\mathrm{E}_{\mathrm{HOMO}}, \\
\mathrm{eV}\end{array}$ & $\begin{array}{c}\text { E }_{\text {LUMO, }} \\
\mathrm{eV}\end{array}$ & $\begin{array}{c}\mathrm{E}_{\text {HOMO-1 }} \\
\mathrm{eV}\end{array}$ & $\begin{array}{c}E_{\text {LUMO+1 }} \\
(\mathrm{eV})\end{array}$ \\
\hline & 247.56 & 5.0083 & 0.0120 & $\mathrm{n} \rightarrow \pi^{*}$ & & & & \\
\hline & 226.81 & 5.4664 & 0.0002 & $\mathrm{n} \rightarrow \pi^{-*}$ & -5.3718 & 0.3298 & -7.0152 & 1.6488 \\
\hline 196.2 & 198.79 & 6.2368 & 0.0100 & $\mathrm{n} \rightarrow \pi^{*}$ & & & & \\
\hline
\end{tabular}

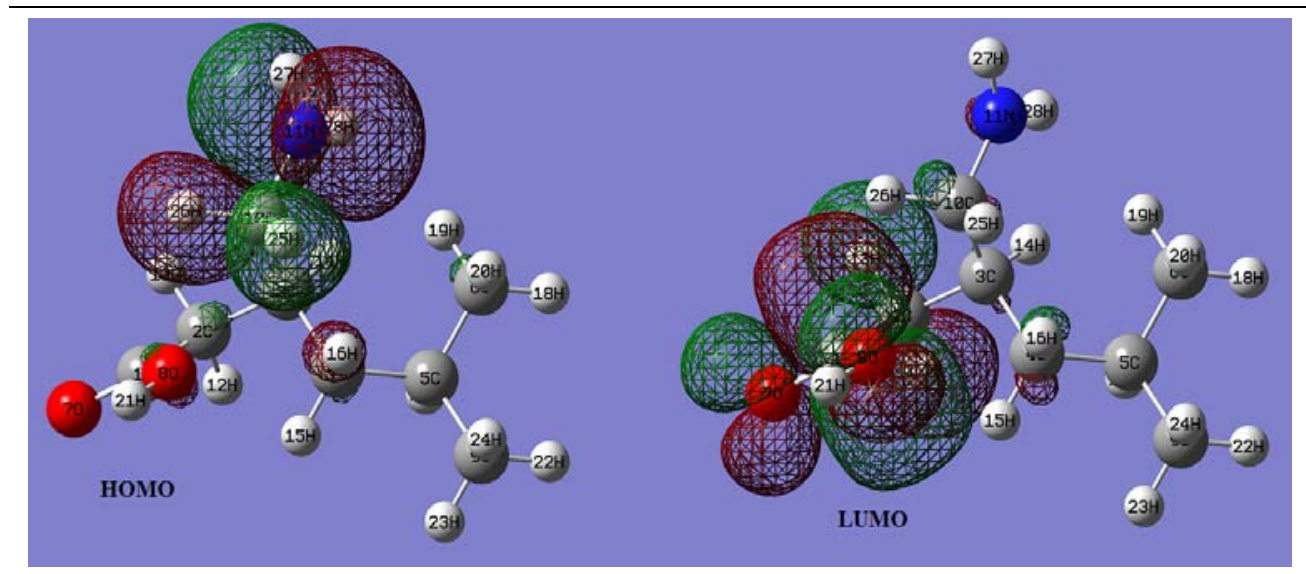

Figure 2. The HOMO and LUMO of pregabalin

\section{Natural population analysis}

The calculation of effective atomic charges plays an important role in the application of quantum mechanical calculations to molecular systems. Our interest here is in the comparison of different methods (DFT-B3LYP/6-31G(d.p)) to describe the electron distribution in pregabalin as broadly as possible and to assess the sensitivity of the calculated charges to changes in the choice of the quantum chemical method. The calculated natural atomic charge values from the natural population analysis (NPA) and Mulliken population analysis (MPA) procedures using the DFT-B3LYP/6-31G(d,p) method are listed in Table 3. The NPA from the natural bonding orbital (NBO) method is better than the MPA scheme. Table 3 compares the atomic charge site of pregabalin from both MPA and NPA methods. The NPA of pregabalin shows that the presence of two oxygen atoms $[\mathrm{O} 7=-0.600 ; \mathrm{O} 8=-0.735]$ imposes large positive charges on the carbon atom $[\mathrm{C} 1=0.818]$. However, the nitrogen atom N11 possess large negative charges, resulting in the positive charges on the hydrogen atoms H27 and H28. Moreover, there is no difference in charge distribution observed on all hydrogen atoms except the $\mathrm{H} 21, \mathrm{H} 27$ and $\mathrm{H} 28$ hydrogen atoms respectively. The large positive charge on $\mathrm{H} 22$ is due to the large negative charge accumulated on the $\mathrm{O} 8$ atom. 
Table 3. Natural atomic charges of pregabalin

\begin{tabular}{ccc}
\hline \multirow{2}{*}{ Atom } & MPA & NPA \\
\cline { 2 - 3 } & B3LYP/6-31G(d,p) & B3LYP/6-31G(d,p) \\
\hline C1 & 0.579 & 0.818 \\
C2 & -0.271 & -0.553 \\
C4 & -0.080 & -0.272 \\
C5 & -0.126 & -0.457 \\
C6 & -0.076 & -0.253 \\
O7 & -0.284 & -0.681 \\
O8 & -0.471 & -0.600 \\
C9 & -0.484 & -0.735 \\
C10 & -0.298 & -0.682 \\
N11 & 0.052 & -0.242 \\
H12 & -0.670 & -0.951 \\
H13 & 0.135 & 0.271 \\
H14 & 0.142 & 0.276 \\
H15 & 0.079 & 0.239 \\
H16 & 0.078 & 0.232 \\
H17 & 0.092 & 0.239 \\
H18 & 0.076 & 0.235 \\
H19 & 0.091 & 0.234 \\
H20 & 0.082 & 0.220 \\
H21 & 0.100 & 0.231 \\
H22 & 0.329 & 0.522 \\
H23 & 0.092 & 0.233 \\
H24 & 0.093 & 0.233 \\
H25 & 0.096 & 0.228 \\
H26 & 0.084 & 0.213 \\
H27 & 0.073 & 0.205 \\
H28 & 0.242 & 0.401 \\
\hline
\end{tabular}

\section{Vibrational analysis}

The FTIR and FT-Raman spectra of pregabalin are shown in Figures 3 and 4. The observed and calculated frequencies using B3LYP/6-31G(d,p) method along with their relative intensities and assignments of pregabalin are summarised in Table 4 . The maximum number of values determined by DFT method is well agreed with the experimental values. Therefore, this method is considered to be more reliable and taken for discussion. The calculated (B3LYP) vibrational spectra were shown in Figure 5. Comparison of the frequencies calculated at B3LYP/6-31G(d,p) with experimental values.

The $\mathrm{CH}, \mathrm{NH}$ and $\mathrm{OH}$ stretching modes are expected to be observed at the high wave number region. The $\mathrm{CH}$ stretching bands are observed between $3073-3049 \mathrm{~cm}^{-1}$ in DFT methods. A very weak band at $3581 \mathrm{~cm}^{-1}$ in DFT was attributed to $\mathrm{NH}_{2}$ asymmetric stretching vibration. The $\mathrm{CH}_{2}$ wagging mode was also identified. Let us start considering the contribution of theoretical methods B3LYP, the $\mathrm{OH}$ stretching mode is predicted at $3744 \mathrm{~cm}^{-1}$ in B3LYP. This OH stretching mode is affected in the presence of water molecules. The $\mathrm{OH}$ stretching vibrational wave number is decreasing in DFT polarization effect inclusion in DFT method. 


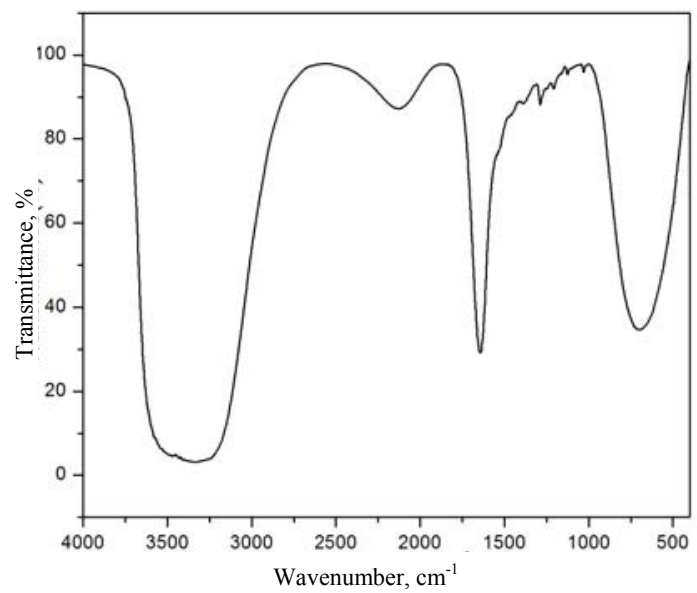

Figure 3. FTIR spectrum of pregabalin

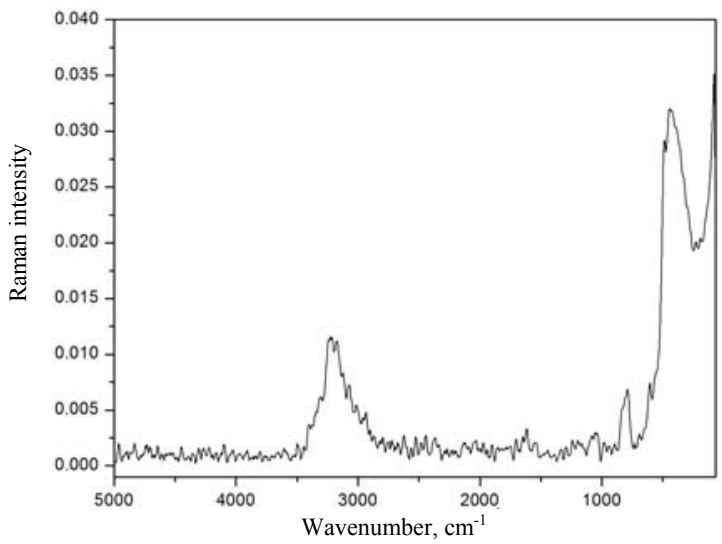

Figure 4. FT-Raman spectrum of pregabalin

Table 4. Selected observed and calculated vibrational assignments of Pregabalin

\begin{tabular}{|c|c|c|c|c|}
\hline \multicolumn{2}{|c|}{$\begin{array}{c}\text { Observed } \\
\text { wavenumber } \mathrm{cm}^{-1}\end{array}$} & \multicolumn{2}{|c|}{$\begin{array}{c}\text { B3LYP/6-31G(d,p) } \\
\text { calculated wavenumber, } \mathrm{cm}^{-1}\end{array}$} & \multirow[t]{2}{*}{ Assignments } \\
\hline TIR & FT-Raman & Theoretical & IR intensity & \\
\hline 700 & 788 & 742 & 42.5 & $\mathrm{CH}$ out of plane \\
\hline \multirow[t]{3}{*}{1030} & 1052 & 1042 & 30.7 & $\mathrm{CH}$ out of plane \\
\hline & & 1071 & 15.0 & $\mathrm{CH}$ out of plane \\
\hline & & 1113 & 57.5 & $\mathrm{CH}$ inplane \\
\hline 1125 & & 1127 & 41.4 & $\mathrm{CH}$ inplane \\
\hline 1207 & & 1204 & 78.0 & $\mathrm{NH}_{2}$ wagging \\
\hline 1288 & & 1286 & 1.7 & $\mathrm{CH}_{2}$ wagging \\
\hline 1387 & & 1382 & 9.5 & $\mathrm{CH}_{2}$ wagging \\
\hline \multirow[t]{2}{*}{1642} & 1614 & 1678 & 29.0 & $\mathrm{NH}_{2}$ scissoring \\
\hline & & 1839 & 238.0 & $\mathrm{C}=\mathrm{O}$ stretching \\
\hline 2135 & & 2960 & 55.2 & $\mathrm{CH}_{3}$ symmetric stretching \\
\hline
\end{tabular}




\begin{tabular}{cccc}
\hline & 3010 & 23.1 & $\mathrm{CH}_{3}$ asymmetric stretching \\
& 3029 & 28.5 & $\mathrm{CH}_{3}$ stretching \\
& 3034 & 17.2 & $\mathrm{CH}_{3}$ stretching \\
& 3044 & 6.8 & $\mathrm{CH}_{3}$ stretching \\
& 3049 & 11.4 & $\mathrm{CH}$ stretching \\
& 3062 & 17.1 & $\mathrm{CH}$ stretching \\
& 3073 & 65.3 & $\mathrm{CH}$ stretching \\
& 3092 & 7.5 & $\mathrm{CH}_{2}$ symmetric stretching \\
& 3096 & 6.0 & $\mathrm{CH}_{2}$ symmetric stretching \\
& 3104 & 73.4 & $\mathrm{CH}_{2}$ symmetric stretching \\
& 3109 & 24.7 & $\mathrm{CH}_{2}$ asymmetric stretching \\
& 3112 & 57.6 & $\mathrm{CH}_{2}$ asymmetric stretching \\
& 3144 & 8.0 & $\mathrm{CH}_{2}$ asymmetric stretching \\
& 3499 & 2.8 & $\mathrm{NH}_{2}$ symmetric stretching \\
& 3581 & 1.8 & $\mathrm{NH}_{2}$ asymmetric stretching \\
& 3744 & 50.3 & OH stretching \\
\hline
\end{tabular}

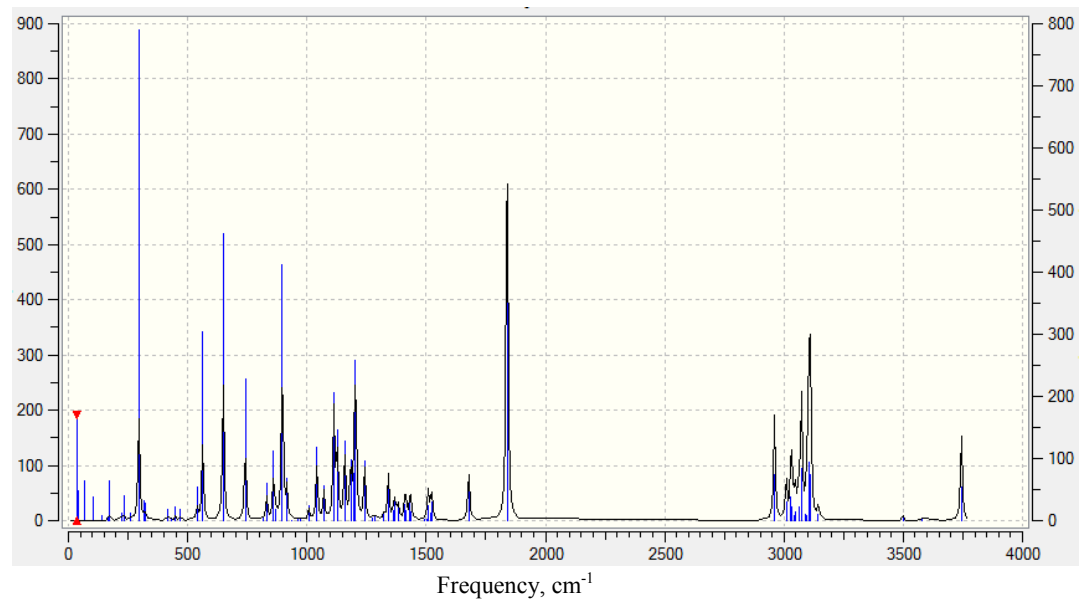

Figure 5. DFT calculated IR spectrum of pregabalin

The $\mathrm{NH}_{2}$ symmetric and asymmetric stretching vibrations in the range $3200-3400 \mathrm{~cm}^{-1}$ are in good agreement with the experimental spectrum. The computed $\mathrm{NH}_{2}$ scissoring vibration at $1678 \mathrm{~cm}^{-1}$ in DFT is excellent agreement with the expected characteristic value $1642 \mathrm{~cm}^{-1}$ in FTIR and $1614 \mathrm{~cm}^{-1}$ in FT-Raman ${ }^{14}$. In the presence of water molecules in the pregabalin, the NH stretching vibrations were red shifted by $10 \mathrm{~cm}^{-1}$. But however, the $\mathrm{NH}_{2}$ scissoring mode was not affected. Also, the $\mathrm{C}=\mathrm{O}$ stretching modes have been assigned at $1839 \mathrm{~cm}^{-1}$ in DFT method. The assumption that the compound group plays very important role in stabilizing the structure of pregabalin.

\section{Methyl group vibrations}

The title molecule pregabalin under consideration possesses one $\mathrm{CH}_{3}$ unit which lies in the terminal group of molecule. For the assignments of $\mathrm{CH}_{3}$ group frequencies, nine fundamentals can be associated to each $\mathrm{CH}_{3}$ group ${ }^{15}$. The $\mathrm{C}-\mathrm{H}$ stretching in $\mathrm{CH}_{3}$ occurs at lower frequencies than those of aromatic ring $\left(3100-3000 \mathrm{~cm}^{-1}\right)$. Moreover, the asymmetric stretch is usually at higher wave number than the symmetric stretch. Methyl group vibrations system, 
the antisymmetric $\mathrm{C}-\mathrm{H}$ stretching mode of $\mathrm{CH}_{3}$ is expected around $3029 \mathrm{~cm}^{-1}$ and $\mathrm{CH}_{3}$ symmetric stretching is expected ${ }^{16,17}$ at $2960 \mathrm{~cm}^{-1}$. The antisymmetric $\mathrm{C}-\mathrm{H}$ stretching mode of $\mathrm{CH}_{3}$ identified at $3010 \mathrm{~cm}^{-1}$ in DFT spectrum.

\section{Thermodynamic properties}

Several calculated thermodynamic parameters are presented in Table 5. Scale factors have been recommended ${ }^{18}$ for an accurate prediction in determining the zero-point vibrational energies and the entropy S. The variation in the ZPVEs seems to be insignificant. The total energies found to decrease with increase of the basis sets dimension. The changes in the total entropy of pregabalin at room temperature at different basis sets are only marginal.

Table 5. The calculated thermodynamic parameters of pregabalin

\begin{tabular}{cc}
\hline Parameter & B3LYP/6-31G(d,p) \\
\hline Total Energy(a.u) & -520.08 \\
Zero point energy(kcal/mol) & 157.715 \\
Rotational Constants $(\mathrm{GHz})$ & 1.408 \\
& 0.695 \\
Entropy & 0.546 \\
Translational & 41.103 \\
Rotational & 30.776 \\
Vibrational & 42.674 \\
Dipole moment(Debye) & 1.8161 \\
\hline
\end{tabular}

\section{Conclusion}

The geometry of pregabalin was optimized with DFT-B3LYP method using 6-31G(d,p) basis set. The complete molecular structural parameters and thermodynamic properties of the optimized geometry of the compound have been obtained from DFT calculations. The NBO analysis of the title compound has been studied by DFT methods. The vibrational frequencies of the compound have been precisely assigned and analysed and the theoretical results were compared with the experimental vibrations. The energies of important MO's, absorption wavelength $\left(\lambda_{\max }\right)$, oscillator strength and excitation energies of the compound were also determined from TD-DFT method and compared with the experimental values. Thus the present investigation provides selected vibrational assignments, structural information and electronic properties of the compound which may be useful to upgrade the knowledge on pregabalin.

\section{References}

1. Benkert, Otto, Hippius, Hanns, Kompendium Der Psychiatrischen Pharmakotherapie (in German) $\left(6^{\text {th }}\right.$ Ed.,) 2006.

2. Portions of the Pfizer Inc. Financial Report, 2010; http://www.sec.gov/Archives/edgar/data/78003/000119312511048877/dex13.htm

3. Drug Enforcement Administration, Department of Justice,"Schedules of Controlled Substances: Placement of Pregabalin into Schedule V. Final rule". Federal Register, 2005, 70(144), 43633-43635.

4. Frisch M J, Trucks G W, Schlegel H B, Scuseria G E, Robb M A, Cheeseman J R, Montgomery J A Jr, Vreven T, Kudin K N, Burant J C, Millam J M, Iyengar S S, Tomasi J, Barone V, Mennucci B, Cossi M, Scalmani G, Rega N, Petersson G A, Nakatsuji H, Hada M, Ehara M, Toyota K, Fukuda R, Hasegawa J, Ishida M, Nakajima T, 
Honda Y, Kitao O, Nakai H, Klene M, Li X, Knox J E, Hratchian H P, Cross J B, Adamo C, Jaramillo J, Gomperts R, Stratmann R E, Yazyev O, Austin A J, Cammi R, Pomelli C, Ochterski J W, Ayala P Y, Morokuma K, Voth G A, Salvador P, Dannenberg J J, Zakrzewski V G, Dapprich S, Daniels A D, Strain M C, Farkas O, Malick D K, Rabuck A D, Raghavachari K, Foresman J B, Ortiz J V, Cui Q, Baboul A G, Clifford S, Cioslowski J, Stefanov B B, Liu G, Liashenko A, Piskorz P, Komaromi I, Martin R L, Fox D J, Keith T, Al-Laham M A, Peng C Y, Nanayakkara A, Challacombe M, Gill P M W, Johnson B, Chen W, Wong M W, Gonzalez C and Pople J A, Gaussian 03, Revision C.02. Gaussian Inc., Wallingford, CT, 2004.

5. Schlegel H B, J Comput Chem., 1982, 3(2), 214-218; DOI:10.1002/jcc.540030212

6. Becke A D, Phys Rev A, 1988, 38, 3098-3100; DOI:10.1103/PhysRevA.38.3098

7. Lee C, Yang W and Parr R G, Phys Rev B, 1988, 37, 785-789;

DOI:10.1103/PhysRevB.37.785

8. Johnson B G and Frisch M J, Chem Phys Lett., 1993, 216(1-2), 133-140; DOI:10.1016/0009-2614(93)E1238-C

9. Hehre W J, Radom L, Schleyer P V R and Pople A J, Ab Initio Molecular Orbital Theory, Wiley, New York, 1986.

10. Dega-Szafran Z, Katrusiak A and Szafran M, J Mol Struct., 2005, 741(1-3), 1-9; DOI:10.1016/j.molstruc.2004.12.062

11. Carl Kemnitz, Chemoffice Ultra 10, Trial Version, 2002.

12. Silverstein R M, Bassler G C and Morrill T C, Spectrometric Identification of Organic Compounds, $5^{\text {th }}$ Ed., John Wiley \& Sons, Inc., New York, 1981.

13. Alka Bali and Prateek Gaur, Chem Cen J., 2011, 5, 59.

14. Ramkumaar G R, Srinivasan S, Bhoopathy T J and Gunasekaran S, Spectrochimica Acta Part A: Molecular Biomolecular Spectroscopy, 2012, 98, 265.

15. Kalsi P S, Spectroscopy of Organic Compounds, Wiley Eastern Limited, New Delhi, 1993.

16. Sajan D, Hubert Joe I and Jayakumar V S, J Raman Spectrosc., 2005, 37(4), 508-519; DOI:10.1002/jrs.1424

17. Gussoni M, Castiglioni C, Ramos M N, Rui M C and Zerbi G, J Mol Struct., 1990, 224, 445-470; DOI:10.1016/0022-2860(90)87033-T

18. Alcolea Palafox M, Int J Quantum Chem., 2000, 77(3), 661-684;

DOI:10.1002/(SICI)1097-461X(2000)77:3<661::AID-QUA7>3.0.CO;2-J 